\title{
Selection Module Q-sorting System of Augmented Reality-based Physical Activity for Developmentally Disabled Children
}

\author{
Jong-Chan Kim ${ }^{1}$, Eung-Kon Kim ${ }^{1}$, Ki-Heon Yoon ${ }^{2}$, So-Hyung Kim ${ }^{3}$, Jin-Woo \\ Park $^{3}$, Dae-Kyung Kim ${ }^{3}$, and Hyun-Su Lee ${ }^{3}$ \\ ${ }^{1}$ Department of Computer Engineering, Sunchon National University, 57922, \\ Korea \\ ${ }^{2}$ Department of Design, Pusan National University, 46241, Korea \\ ${ }^{3}$ Department of Physical Education, Pusan National University, 46241, Korea \\ ${ }^{1}$ Email: seaghost@sunchon.ac.kr, ${ }^{3}$ Email:s3airlee@pusan.ac.kr
}

\begin{abstract}
Generally, physically disabled people are vulnerable to secondary health problems or all sorts of adult diseases such as obesity and hyperlipidemia because their physical, mental, and emotional limitations lead to insufficient physical activities. Physical activities in this context include all developmental aspects including psycho-motor, cognitive, and affective aspects. Through these interactions, physical development can be promoted. This paper aims to develop the selection module $Q$-sorting system of physical activities, which triggers developmentally disabled children's activity choice. This is reflected in their self-determination by standing on the basis of augmented reality beyond limited physical activity pictures or card representation. The research will contribute to recognizing a theoretical framework and academic implications for the following study regarding self-determination of developmental challenged children.
\end{abstract}

Keywords: Q-Sorting System, Augmented Reality, Selection Module, Developmentally Disabled Children, Physical Activity

\section{Introduction}

"Europe and North America have recently become greatly interested in the selfdetermination of the physically and mentally challenged. For a person with impairment and also for their family, self-determination plays an essential role in their quality of life. For the of an individual's quality of life, becoming an agent of one's life is not trivial in that all choices and decisions are dedicated to determining physical, psychological, and social quality of life.

Physical activities belong to a broad concept that includes exercise, i.e., body movements caused by the contraction of skeletal muscles driven by energy consumption. Not only sports, but also shrewd movements such as active playing, dancing, and everyday activities are also included in this category[1-2].

In terms of participation in physical activities in the rehabilitation and welfare paradigm, the model that focuses on disabled people's own choice and selection of physical activities is emphasized. These efforts are linked to improving the quality of life for the physically and mentally challenged so that they have the same conditions as common people and also physical, emotional, and social literacy reinforcement.

Furthermore, the viewpoint of the PE scene and its academic area for the physically challenged changed from quantitative, result-oriented, and group-centered into qualitative, process-oriented, and individualized, which led us to attempt to research this. Along with economic growth, social climates have pushed the "welfare paradigm for citizen" that emphasizes human rights and self-realization in the issue of social policy[3],[4]. 
As a result, the physical environment for disabled people has changed in order to help them lead a more happy and prosperous life. This change concerns the way in which common people approach the physically and mentally challenged, that is with more acceptance and acknowledgment, and not with fundamental elimination. The disabled, can harmonize with others as community members, and cultivate their competences as individuals who are considered significant. With systematic pedagogical designs and interaction with other children, developmentally challenged children can learn in a selfdirected way and this can motivate their participation and enhance self-esteem.

Research into special physical education regarding self-determination of the physically challenged has not been conducted in a sufficient manner. Regarding on-site education, children with developmental disabilities tend to develop self-determination more slowly when compared to other children, thus, they are likely to be unsure of their decisions, or their self-determination might be considered absent to themselves and their acquaintances.

Self-determination is invaluable in allowing a person to lead an independent life because it is directly associated with quality of life. In educational environments, by letting children choose based on their preferences, self-determination offers them the opportunity to pursue a satisfactory life. Developmental disability includes both mental and physical disorders, language impediments, sensory impairments (both auditory and visual), and other learning disorders caused by innate or cerebral injury during the developmental process.

This study developed a selection module Q-sorting system of augmented reality-based physical activity for children with developmental disabilities so as to improve indirect/direct physical activity, with the final aim of providing a supplementary learning tool connected with movement. It can also help select physical activities, as it reflects disabled children's opinions or self-determination. We use a selection module Q-sorting system to facilitate immersion and to increase the learning effect beyond more limited picture cards by offering information on physical activities to developmentally disabled students. This research could later be expanded on by using this technique in different subject areas such as artistic education.

\section{Related Works}

\subsection{Augmented Reality}

Augmented reality is a technique that adds a virtual object in the visible real world. It is also called mixed reality (MR) because it presents the merging of virtual and real worlds through live streaming. The first research into developing this see-through technology came by means of the HMD (head mounted display), invented by Ivan Sutherland. Later, Ronald Azuma's design combined images of real-world elements and virtual reality, so that it was possible to interact in real-time [6-7].

Augmented reality is a technique which adds a virtual object on the visible real world. Also, it is called mixed reality (MR) because it presents one projection mixing additional virtual images with the real world through live.

The first research was developing see-through HMD (head mounted display) by Ivan Sutherland. Then, Ronald Azuma's design is a combination of images of real-world elements and virtual reality's, possible to interact in real time. Ronald Azuma defines augmented reality as having three features: first, it combines real world elements and virtual reality, (most basic and common characteristics); second, it should be a real time interaction. Through users' viewpoint or movement, live information emphasizes an overlap into the real world; third, it is expressed as 3D images. Considering the previous literature, augmented reality can be defined as the combination of technology together with user interaction [8]. 
The types of augmented reality are classified into three groups: display, business form, and representation setting place. The first includes handheld-based displays, see-through HMDs, and projection-based displays, based on its characteristics of device [6], [9],[10].

Table 1. Main Technologies within the Augmented Reality Field

\begin{tabular}{|c|c|c|}
\hline Tracking & Rendering & Display \\
\hline $\begin{array}{c}\text { Recognizing } \\
\text { markers and tracking } \\
\text { virtual objects }\end{array}$ & $\begin{array}{c}\text { Creating/ } \\
\text { Transferring/ } \\
\text { Removing virtual } \\
\text { objects }\end{array}$ & $\begin{array}{c}\text { Presenting } \\
\text { information on a screen }\end{array}$ \\
\hline $\begin{array}{c}\text { Recognizing } \\
\text { characteristics of } \\
\text { markers and their } \\
\text { surroundings }\end{array}$ & $\begin{array}{c}\text { (virtual objects) and } \\
\text { sound }\end{array}$ & $\begin{array}{c}\text { Makeball player's form } \\
\text { coordination with } \\
\text { reality }\end{array}$ \\
\hline
\end{tabular}

Among the different types of displays, handheld-based displays have high mobility and they are actively being researched due to increased mobile phone use. See-through HMDs offer the most similar and familiar realization form, namely, the way humans look at objects. These have disadvantages such as discomfort (e.g., wearing them on your head) and limitations given by the angles of view. Meanwhile, projection-based displays benefit simultaneous watching, but limit mobility, vision, or distance from placement. The main technologies using augmented reality include tracking, rendering, and display see Table 1.

Tracking is a technology of marker recognition for matching virtual objects with the screen, while rendering, on the other hand, is a computer-generated imagery adding virtual reality (VR) to the real world. In this process, smooth coordination is quite a significant task and a virtual object should be focused on the coordinate to lessen visual discordance. Camera adjustment and capturing accurate parameters are needed to synthesize virtual objects in comparable stabilized images in real time. Display technology - presenting information on the screen - is divided into HMD and non-HMD. Augmented reality can be applied to games, advertisements, education, medicine, sightseeing, art, etc. Along with the proliferation of mobile media, interface development is heightened as well.

\subsection{Self-determination Theory}

The term self-determination has been used for a long time in politics, law, psychology, and provides a useful framework for research in various fields such as in human relationships, education, work, sports, and leisure. Self-determination in special education and physical education has recently captured a lot of attention. The philosophical origin of the concept traces back to philosophers in the 18th century Illuminism-age. Their ideas of "human reason" can be understood as the precursors to today's notion of selfdetermination, i.e., determining one's behaviors[5]. 
Self-Determination Theory (SDT) was developed by researchers Edward L. Deci and Richard M. Ryan. Figure 1 is concerns with human motivation, personality and optimal functioning. Rather than just the amount of motivation, self-determination theory focuses on different types of motivation. Since positive psychology deals with positive emotions and ways to nurture individual's strengths, SDT is useful in merging a good amount of work in positive psychology. SDT claims that people have three innate psychological needs which are considered as universal necessities. SDT also asserts that there are different approaches to motivation, and differentiates between different types of motivation[13].

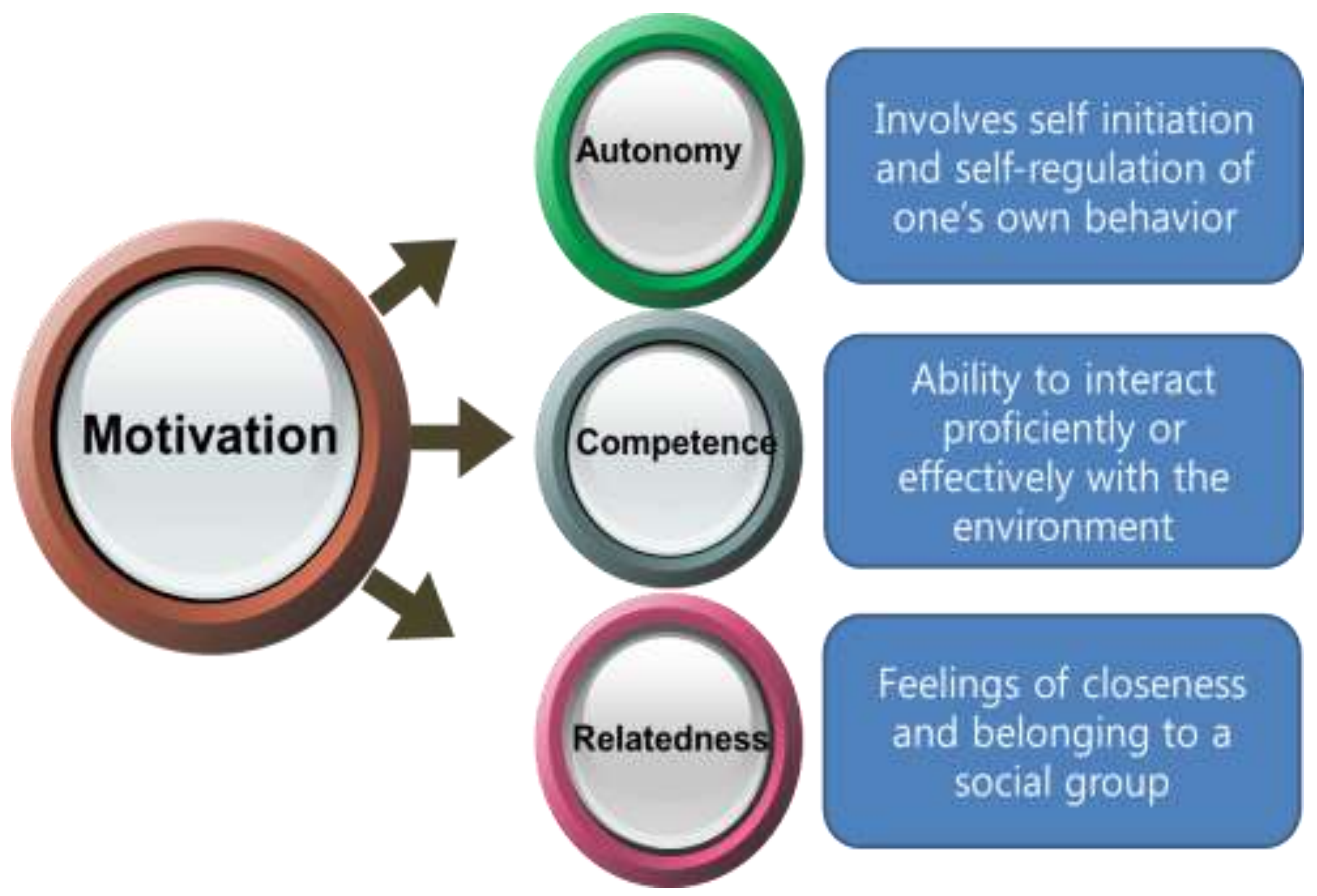

Figure 1. Self-Determination Theory(SDT): Antecedents of Motivation

Self-determination of disabled people is an index for the level of a country's welfare and has been researched in relation to their quality of life. Disabled people and their families have agreed that self-determination would be key in giving their lives direction. In order to improve quality of life, becoming an agent of one's life is a prerequisite, and all choices and decisions contribute to determine physical, psychological, and social life quality.

\subsection{Harr-like feature}

The face images input from the camera are much affected by the various external environmental factors. In environmental factors face detection method in which robust and fast computation is possible is required. As the features for the detection Haar-like Feature was used as the set of characteristics for the object detection. Haar-like feature can be computed quickly using the integral image. Using this Haar-like feature and the integral image, they can be used effectively in real-time object detection where are required the reduction of complex operations, and a high detection performance . 


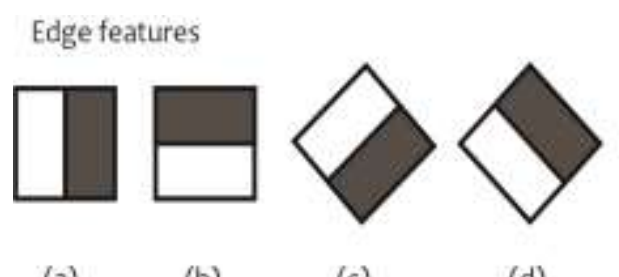
(a)
(b)
(c)
(d)

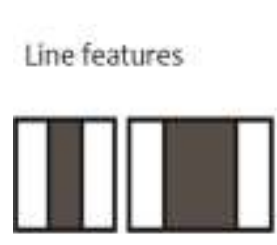

(a)

(b)

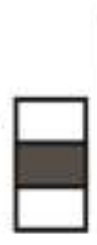

(c)

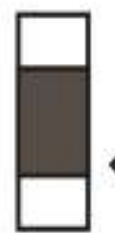

(d)

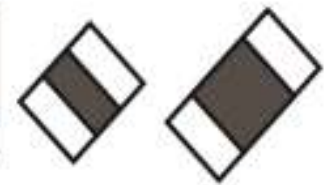

(e)

(f)

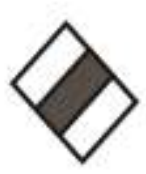

(g)

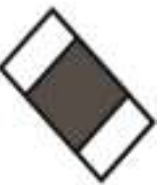

(h)

Center-surround features

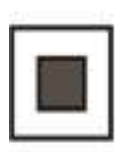

(a)

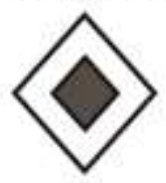

(b)

Figure 2. Haar-like Features from the OpneCV Source Distribution

Figure 2 shows the representative Haar-like features, which are classified as edge features, line features, and center surround features. In the most basic edge features, the feature value of (a), (b) is represented by the difference between two sums- the sum of all pixel values in the bright part and the sum of all the pixel values in the dark areas. (c) can be obtained by the difference between the sum of all pixel values in the outside bright part and the sum of all pixel values in the central dark part, and (d) can be obtained by the difference between the sum of all pixel values in the bright part of the diagonal direction and the sum of all pixel values in the dark part[11-12].

$$
i i(x, y)=\sum_{x^{\prime} \leq x, y^{\prime} \leq y} i\left(x^{\prime}, y^{\prime}\right)
$$

In equation (1) $\mathrm{ii}(\mathrm{x}, \mathrm{y})$ is integral image, $\mathrm{ii}\left(\mathrm{x}^{\prime}, \mathrm{y}^{\prime}\right)$ is the brightness value of the initial image. Point $4(\mathrm{x}, \mathrm{y})$ 's value can be obtained by all cumulative pixel values to the horizontal $\mathrm{x}$ coordinate, and to the vertical y coordinate.

In Figure 3, the sum of the pixels within rectangle D can be computed with four array references. The value of the integral image at location 1 is the sum of the pixels in rectangle $\mathrm{A}$. The value at location 2 is $\mathrm{A}+\mathrm{B}$, at location 3 is $\mathrm{A}+\mathrm{C}$, and at location 4 is $\mathrm{A}$ $+\mathrm{B}+\mathrm{C}+\mathrm{D}$. The sum within $\mathrm{D}$ can be computed as $4+1-(2+3)$. 


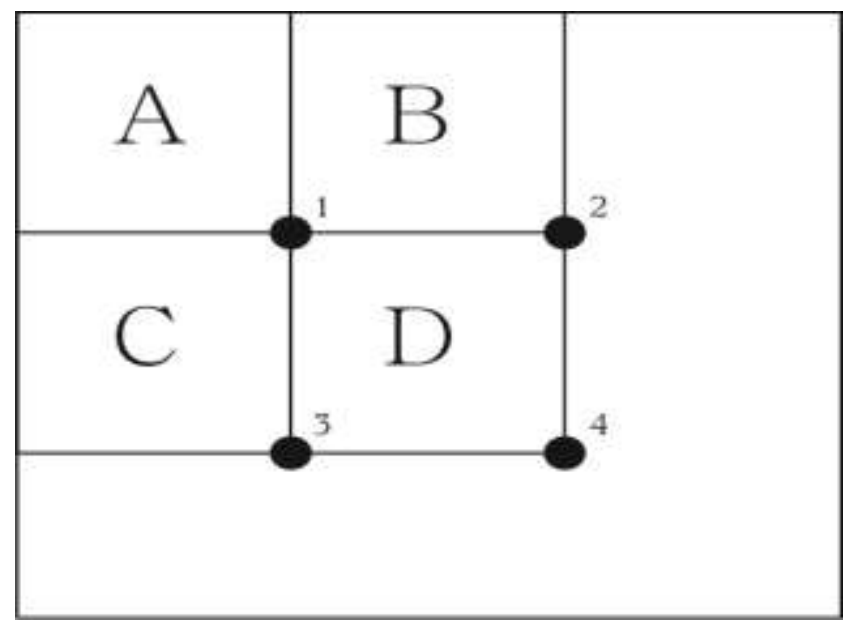

Figure 3. Rectangular Regions of an Integral Image

\section{Selection Module Q-Sorting System of Physical Activity}

\subsection{Analysis of Preference to Physical Activities}

Types of physical activities were selected from a textbook for disabled children, preresearches related for Q-sorting. We excluded overlapping or similar exercises; twentyfour activities were chosen in the end, and divided into four categories: competition, basics, instrument, and cooperation.

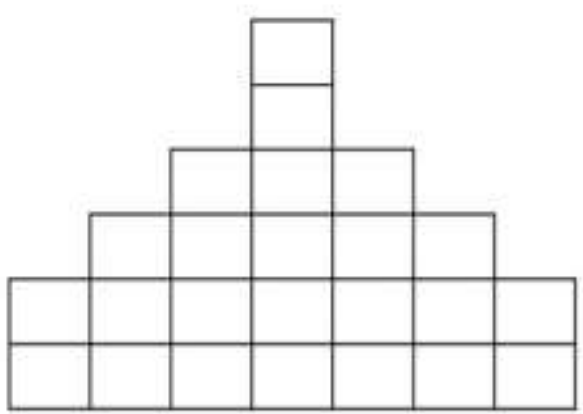

$\begin{array}{lllllll}-3 & -2 & -1 & 0 & +1 & +2 & +3\end{array}$

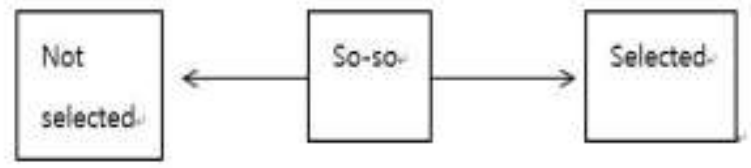

Figure 4. Q-sorting and its Scores

Q-sorting is the process we used to identify disabled children's preferences for different physical activities from the 24 picture cards. Every participant's characteristics were taken into account; Q-sorting was adapted for the severely impaired children. Participants could answer in the following three ways: "I would like to do," "I would not like to do," or "I do not know." After being asked the question "what do you most like to do?" while looking at their "I would like to do" cards, their responses were classified into the +3 row. We then showed them the remaining cards and they responded to the question 
"what do you most like to do?" Second type matching progressed in the same manner, and finally, "so-so" cards were distributed. Figure 4 presents Q-sorting and its scores.

\subsection{Selection Module Q-sorting System Design of Physical Activities with Picture Cards}

The Q-sorting system was formed as shown in Figure 5, so that developmentally disabled children could choose picture cards easily.

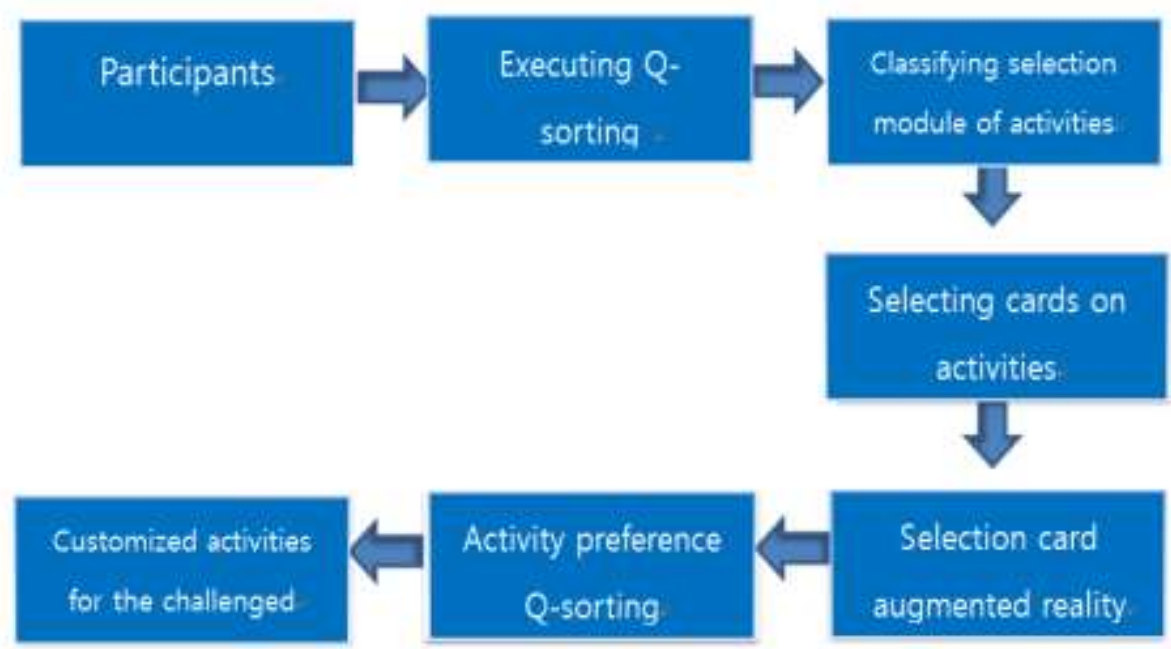

Figure 5. Selection Module Q-sorting System of Physical Activities for Developmentally Disabled Children

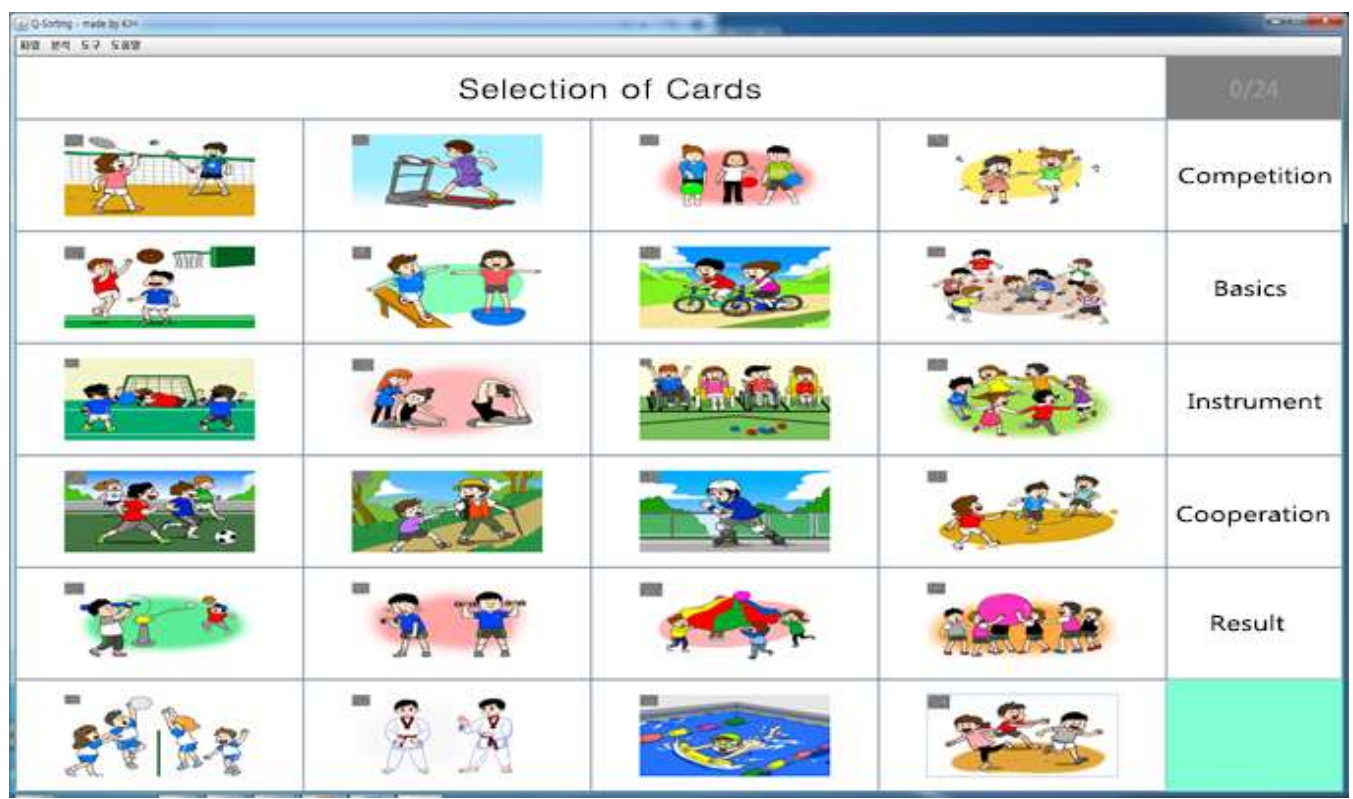

Figure 6. 24 Cards of Physical Activities

Activities were divided into competition, basics, instrument, and cooperation activities. Prioritizing the favorite cards for each module we repeated this six times and the results were sorted on the analyzing screen. Based on the children's preferences and their selfdetermination, tailored physical activities were constructed. After downloading the 
installation program via a website or cable, web-based programs were executed without installing a device.

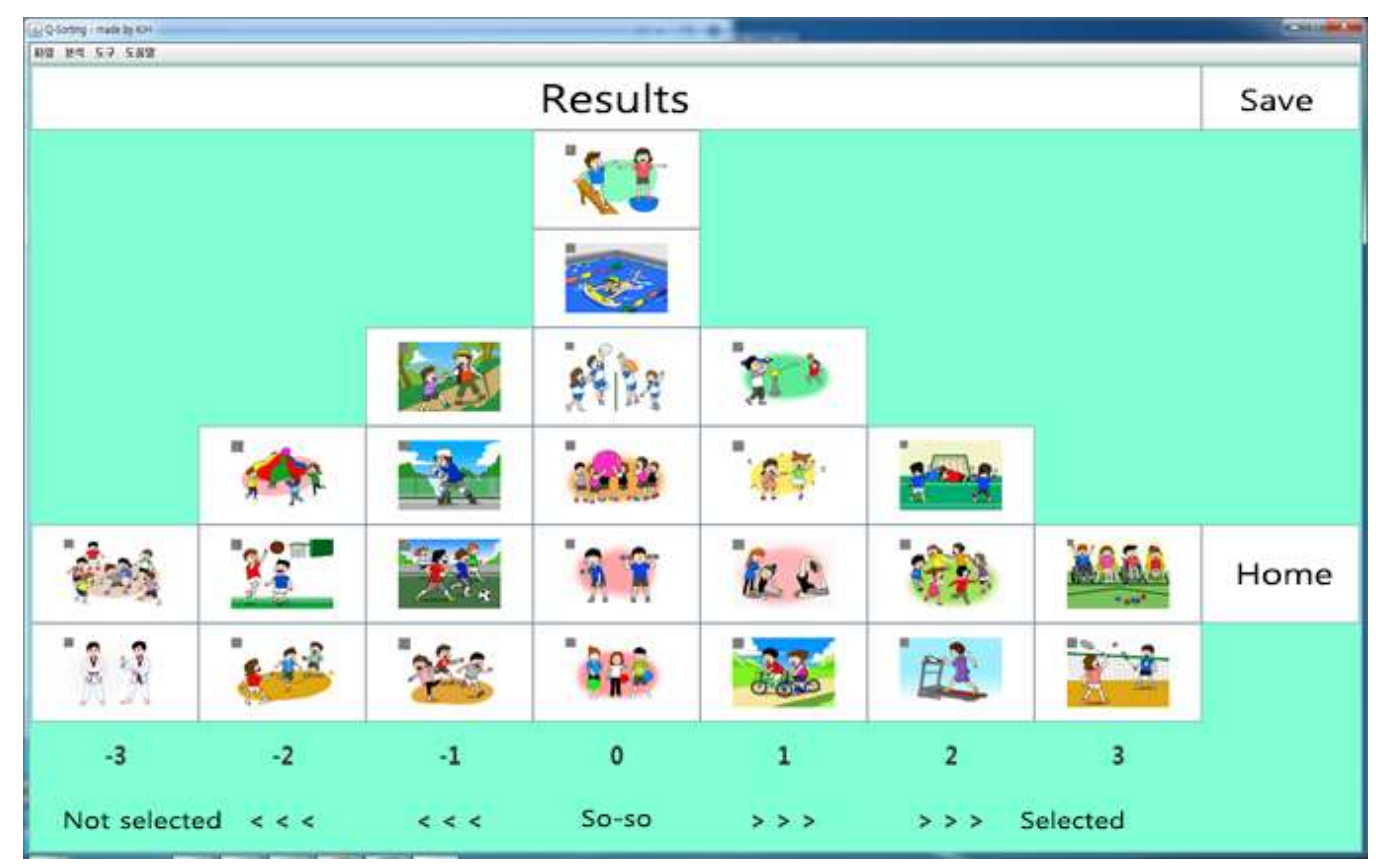

Figure 7. Selection Module Q-sorting Realization
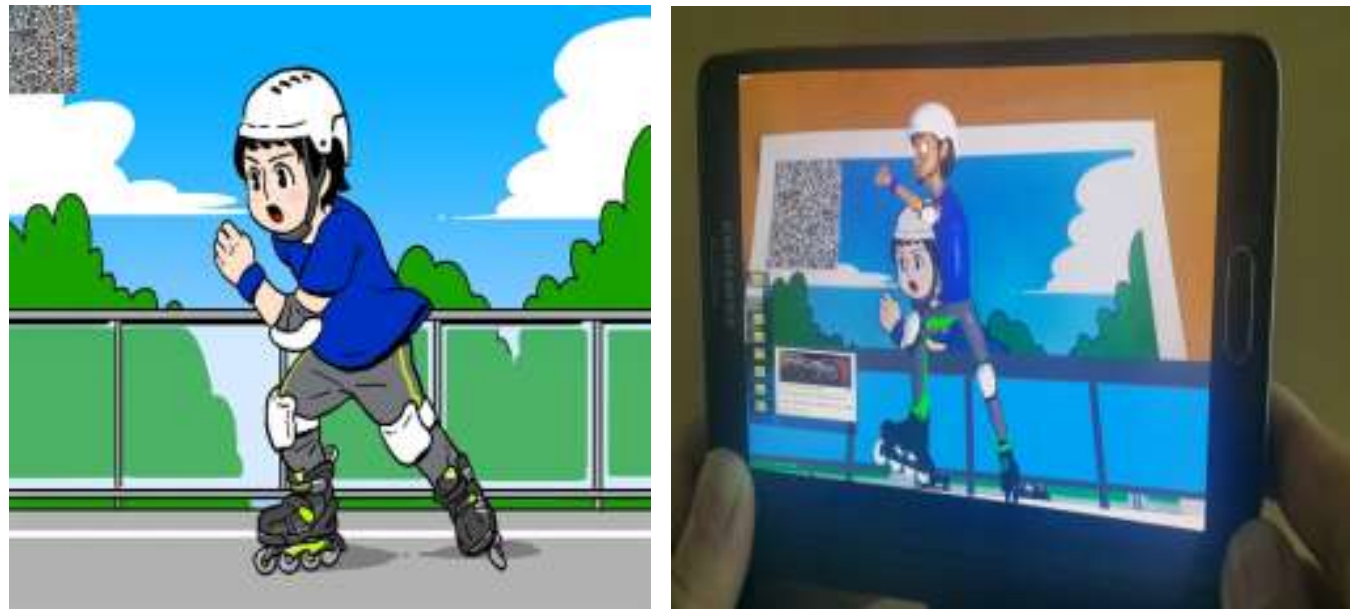

Figure 8. Augmented Reality-based Inline Skates

Figure 6 shows the realization of the 24 picture cards, and Figure 7 shows the selection module Q-sorting for developmentally challenged students. In the realization setting, the concrete computer hardware specification was Intel Core i5-2500 and 4GB RAM, ATi Radeon HD 3800 VGA; the manufacturing software was 3D Max, Illustrator 6.0; the operational system was Microsoft Windows 7 x64, Eclipse IDE, JDK 1.7. Please note that, JRE (Java Runtime Environment) does not support versions below-1.5.0 for a safe operation of the system. Figure 8 indicates the result of materializing augmented realitybased inline skate among the collections. 


\section{Conclusions}

This paper used an augmented reality-based selection module Q-sorting system for developmentally challenged children, based on interdisciplinary convergence research and experiences in special physical education. Beyond current limited pictures or cards on body movements, selection activities with self-determination of the disabled can be induced. This implies that customized selection possibilities for the developmentally impaired in the digital age are possible, and a new direction to the support module development can be used. Applying augmented reality into special education can supplement limited therapy without spatial-temporal restrictions.

In other words, the system can provide different activities to children in growth and also to disabled senior citizens. Future research needs to concentrate on constructing a theoretical framework and academic significance in order to apply the selection module of augmented reality-based physical activities to developmentally challenged children and perhaps also to other people in need.

\section{Acknowledgments}

This work was supported by the Ministry of Education of the Republic of Korea and the National Research Foundation of Korea (NRF-2015S1A5B6037183).

\section{References}

[1] H. M. Kim, S. H. Kim, J. W. Park, and H. S. Lee, "Investigation of Sports for All Requirement Types of People with Intellectual Disability: Focused On Q Methodology", The Korean Journal of Physical Education, vol. 54, no. 1, (2015), pp. 597-609.

[2] J. S. Park, S. M. Yun, and H. S. Lee, "The Effect of Physical Activity Program of Move Grow on Recognition Ability and Emotional Behavior in Mentally Disabled People", Journal of Korean Society of Sport and Leisure Studies, vol. 3, no. 1, (2009), pp. 899-909.

[3] H. S. Lee, and S. H. Kim, "Exploration on the Applicability of Q methodology in Research in APA", Korean Journal of Adapted Physical Activity, vol. 20, no. 4, (2012), pp. 31-44.

[4] S. H. Kim, and H. S. Lee, "Preservice Physical Education Teacher's Attitudes toward Inclusive Physical Education: Focused On Q methodology", The Korean Journal of Physical Education, vol. 52, no. 2, (2013), pp.557-568.

[5] K. S. Kim, A. R. Oh, and K. M. Koo, "The Development of a Model to Sport for All on Persons with Disabilities", Korean Journal of Adapted Physical Activity, vol. 17, no. 1, (2009), pp. 65-95.

[6] J. H. Lee and E. H. Lee, "Augmented Reality as an Emotional Communication media on Fashion Communication", Journal of Korea Society of Design Forum, vol. 32, (2011), pp. 7-20.

[7] V. Teichrieb, "A Survey of Online Monocular Markerless Augmented Reality", International Journal of Modeling and Simulation for The Petroleum Industry, vol. 1, no. 1, (2007), pp. 1-7.

[8] J. I. Lee and S. H. Yoo, "Implementation and Application of Fairy-Tale Book of an Augmented Reality Based on Smartphone and Web Browser", Journal of Korea Association of Information Education, vol. 16, no. 2, (2011), pp. 201-209.

[9] S. Park, H, J. Choi, M. S. Kim, D. W. Kim and Y. H. Seo, "Design and Implementation of Digital Hologram Content Using Modified Depth Information", Journal of information and communication convergence engineering, vol. 12, no. 2, (2014), pp. 122-127.

[10] M. C. Lee, K. Inoue, and M. J. Cho, "Three-Dimensional Automatic Target Recognition System Based on Optical Integral Imaging Reconstruction," Journal of information and communication convergence engineering, vol. 14, no. 1, (2016), pp. 51-56.

[11] W. J, Lee, J.C. Kim, and B. H. Lee, "Real-time Face Detection and Tracking using the AdaBoost Algorithm," Jouranl of Korea Multimedia Society, vol. 9. no. 10, (2006), pp. 1266-1275.

[12] P. Viola, and M. J. Jones, "Robust Real-Time Face Detection", International Journal of Computer Vision, vol. 57, no. 2, (2004), pp. 137-154.

[13] R. M. Ryan and E. L. Deci, "Intrinsic and Extrinsic Motivations: Classic Definitions and New Directions”, Contemporary Educational Psychology, vol. 25, (2000), pp. 54-67. 


\section{Authors}
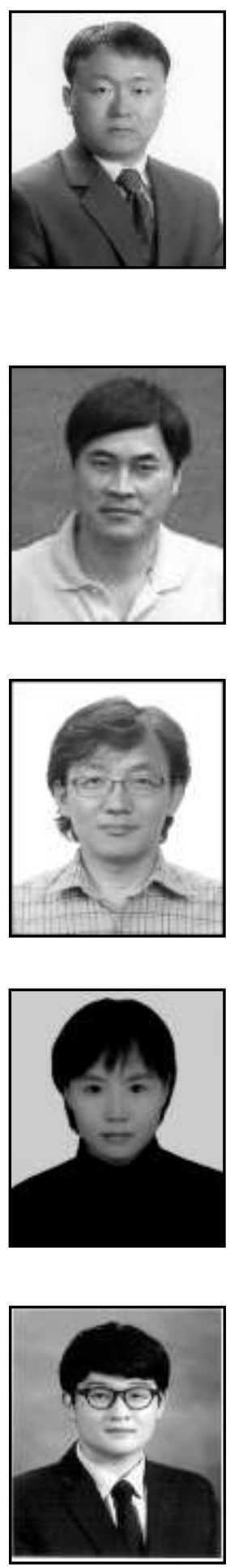

Jong Chan Kim, He received his B.S. degree from Sunchon National University in 2000, his M.S degree from department of computer science, Sunchon National University in 2002, his $\mathrm{Ph} . \mathrm{D}$. degree from the Department of Computer Science, Sunchon National University in 2007. He's a senior research professor of the Automation and System Research Institute at Seoul National University in 2013. His current research interests are image processing, computer graphics, digital clothing, AR, games and HCI.

Eung Kon Kim, He received his B.S. degree from Chosun University, Gwangju,, Korea, in 1980, his M.S degree from The Department of Electronics, Hanyang University, Seoul, Korea, in 1987, and his Ph.D. degree from Chosun University, Gwangju, Korea, in 1992. . Currently, he is a professor in the Department of Computer Engineering, Sunchon National University, Korea. His current research interests are computer vision, virtual reality, image processing, and computer graphics.

Ki-Heon Yoon, He received his B.S. Degree from Seowon University in 1992, his M.S. degree from the Department of Comics, Kyoto Seika University in 2002, and his Ph.D. degree from the Department of Design, Kyoungpook National University in 2012. His current research interests are Animation, Comics and Storytelling.

So-Hyung Kim, She received her B.S. Degree from Korea National Open University in 2004, her M.S. degree from the Department of Special Education, Changwon National University in 2008, and her Ph.D. degree from the Department of Physical Education (Specialization: Adapted Physical Education), Pusan National University in 2015. Her current research interests are Adapted Physical Activity, Adapted Physical Education and Physical activity for disabled children.

Jin-Woo Park, He received his B.S. degree from Kyung-Sung University in 2010, his M.S degree from the Department of Physical Education, Pusan National University in 2012, and his Ph.D. degree from the Department of Physical Education, Pusan National University in 2016. He became a part-time instructor of the Adapted Physical Activity at Pusan National University in 2016. His current research interests are Adapted Physical Activity, Adapted Physical Education and Social Psychology. 

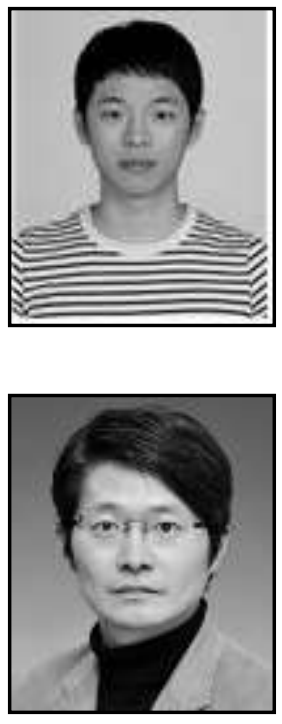

Dae-Kyung Kim, He received his B.S degree from the Department of Adapted Physical Activity, Dongeui University in 2013, his M.S degree from the Department of Physical Education, Pusan National University in 2015, and He's doing a Ph.D. in the Pusan National University. His current research interests are Adapted Physical Activity, social psychology, health care, Rehabilitation Sport.

Hyun-Su Lee, He received his B.S. Degree from Pusan National University in 1998, his M.S. degree from the Department of Physical Education (Specialization: Adapted Physical Education), Pusan National University in 2002, and his Ph.D. degree from the Department of Physical Education (Specialization: Adapted Physical Education), Pusan National University in 2006. He became Associate Professor of Department of Physical Education at Pusan National University in 2009. His current research interests are Adapted Physical Activity, Adapted Physical Education and Disability Sport. 
International Journal of $u-$ and e- Service, Science and Technology Vol.10, No.6 (2017) 